\title{
Combustion Synthesis of Doped Lanthanum Gallate as an Electrolyte for Solid Oxide Fuel Cells
}

\author{
Hiroyuki Ishikawa $^{1, *}$, Makiko Enoki ${ }^{2}$, Tatsumi Ishihara ${ }^{2}$ and Tomohiro Akiyama ${ }^{1}$ \\ ${ }^{1}$ Center for Advanced Research of Energy Conversion Materials, Hokkaido University, Sapporo 060-8628, Japan \\ ${ }^{2}$ Department of Applied Chemistry, Faculty of Engineering, Kyusyu University, Fukuoka 812-8581, Japan
}

Solid oxide fuel cells, SOFCs, have attracted worldwide attention from wide applicability in a large-sized power plant, a distributed power supply, and an efficient cogeneration apparatus with extremely high efficiency of power generation. Doped-lanthanum gallate ( $\left.\mathrm{La}(\mathrm{Sr}) \mathrm{Ga}(\mathrm{Mg}) \mathrm{O}_{3}\right)$, which has been recently proposed as a new solid electrolyte, replaces Yttria Stabilized Zirconia (YSZ), lowers the operating temperature of SOFC and then improves the mechanical reliability of the cells. In this study, the doped-lanthanum gallate was produced by combustion synthesis and its sintering behavior, the electrical conductivity, and life cycle assessment of this process from energy requirement and a carbon dioxide emission were analyzed by comparing with the conventional solid-state method. In the experiments of the combustion synthesis, lanthanum oxide, strontium carbonate, gallium oxide, metallic magnesium, and sodium perchlorate were well mixed with different substitution ratios of gallium by magnesium; $80,60,40$, and $30 \mathrm{~mole} \%$, by using a ball mill and were ignited at one end of the mixture at nitrogen atmosphere to complete the combustion wave propagation of the exothermic reaction to the other end without any additional energy. As a result, all of the products, except the 80 mole\% magnesium-containing lot, showed definite peaks of intermediates containing lanthanum gallate in X-Ray Diffraction (XRD) patterns. Most significantly, the product containing 30 mole\% magnesium, which was completely sintered at $100 \mathrm{~K}$ lower temperature $(1673 \mathrm{~K})$ compared to the solid state method $(1773 \mathrm{~K})$, showed the highest electrical conductivity, $0.08 \mathrm{Scm}^{-1}$ at $1073 \mathrm{~K}$ without the dependency of oxygen partial pressure, being almost the same as the world record. The results demonstrated that the combustion synthesis of SOFC electrolyte had the possibility of an innovative production process with several benefits, such as shortening of processing time, minimizing energy requirement and carbon dioxide emission, and deriving the excellent property of SOFCs.

(Received August 25, 2005; Accepted November 16, 2005; Published January 15, 2006)

Keywords: Solid Oxide Fuel Cell (SOFC), combustion synthesis, doped lanthanum gallate (La(Sr)Ga(Mg)O $\left.\mathrm{O}_{3}\right)$, perovskite type oxide, electrolyte, electrical conductivity

\section{Introduction}

Solid oxide fuel cells (SOFCs) are a promising technology for electrical power generation from high efficiency of power generation with utilization of a variety of fuel resources. In the SOFC system, yttria stabilized zirconia (YSZ) has been typically used as an electrolyte in high-temperature operations; being approximately $1273 \mathrm{~K}$. Recently, a new SOFC has been also developed for intermediate-temperature application. It offers flexible design of the SOFC system with cost benefit, because the structural materials for the system are widely selective by releasing the temperature constraints for the electrolyte. In developing the electrolyte for the intermediate-temperature SOFC, a lanthanum gallate perovskite oxide doped with strontium on the lanthanum site and magnesium on the gallium site, described as $\mathrm{La}_{1-x} \mathrm{Sr}_{x} \mathrm{Ga}_{1-y} \mathrm{Mg}_{y} \mathrm{O}_{3}$ (LSGM), has been reported as suitable materials from both points of its high oxide ion conductivity and stability even under a wide range of an oxygen pressure at an intermediate temperature below $1073 \mathrm{~K}$. In particular, $\mathrm{La}_{0.9} \mathrm{Sr}_{0.1} \mathrm{Ga}_{0.8} \mathrm{Mg}_{0.2} \mathrm{O}_{3}$ is well known as the most suitable electrolyte in SOFC, ${ }^{1-3)}$ that is, it showed the highest electrical conductivity among the ones reported until now. However, generally speaking, the old-fashioned production method of the SOFC materials is still taken in spite of some drawbacks. For example, all of the samples, reported in reference No. 1 to 3, were produced by so-called, solid sate method (SSM). This is highly time- and energy-consuming, for keeping well-mixed, compressive raw materials over six hours at $1273 \mathrm{~K}$ for calcinations as a first phase and over six

*Graduate Student, Hokkaido University hours at $1773 \mathrm{~K}$ for sintering as a final phase. To overcome the drawbacks of this conventional production method, combustion synthesis $(C S)^{4-6)}$ has been proposed as an alternative process, by synthesizing new SOFC materials; for example, doped-lanthanum chromite $\left(\mathrm{La}_{1-x} \mathrm{Sr}_{x} \mathrm{CrO}_{3}\right)^{7)}$ and doped-lanthanum manganite $\left(\mathrm{La}_{1-x} \mathrm{Sr}_{x} \mathrm{MnO}_{3}\right){ }^{8}{ }^{8}$ The principle of the CS is to utilize strong exothermic reaction among raw materials. Once one end of the sample is ignited, the combustion wave propagates to the other end of the sample without any additional energy. From the results reported, we can expect that the processing time drastically shorten, ranging from several seconds to dozens of seconds, together with great reduction of the energy requirement and improvement of the SOFC property. Therefore, the purpose of this paper is to study the possibility of the CS to produce LSGM production in comparison to the conventional method, in which the oxidation heat of metallic magnesium was utilized and the effect of the mixing molar ratio of magnesium on the product was chiefly examined. The proposed CS was compared to the conventional SSM from the both aspects of primary energy consumption and carbon dioxide emission involved the production process of each raw material. In addition, the sintering behavior of combustion-synthesized LSGM in the final phase and the electrical conductivity of the product were studied.

\section{Experiment}

\subsection{Sample preparation}

Figure 1 shows the comparison between the conventional system and the proposed one for producing LSGM. In the CS, the combustion wave that moves out from the ignition point 
(a) Conventional Slid-State Method

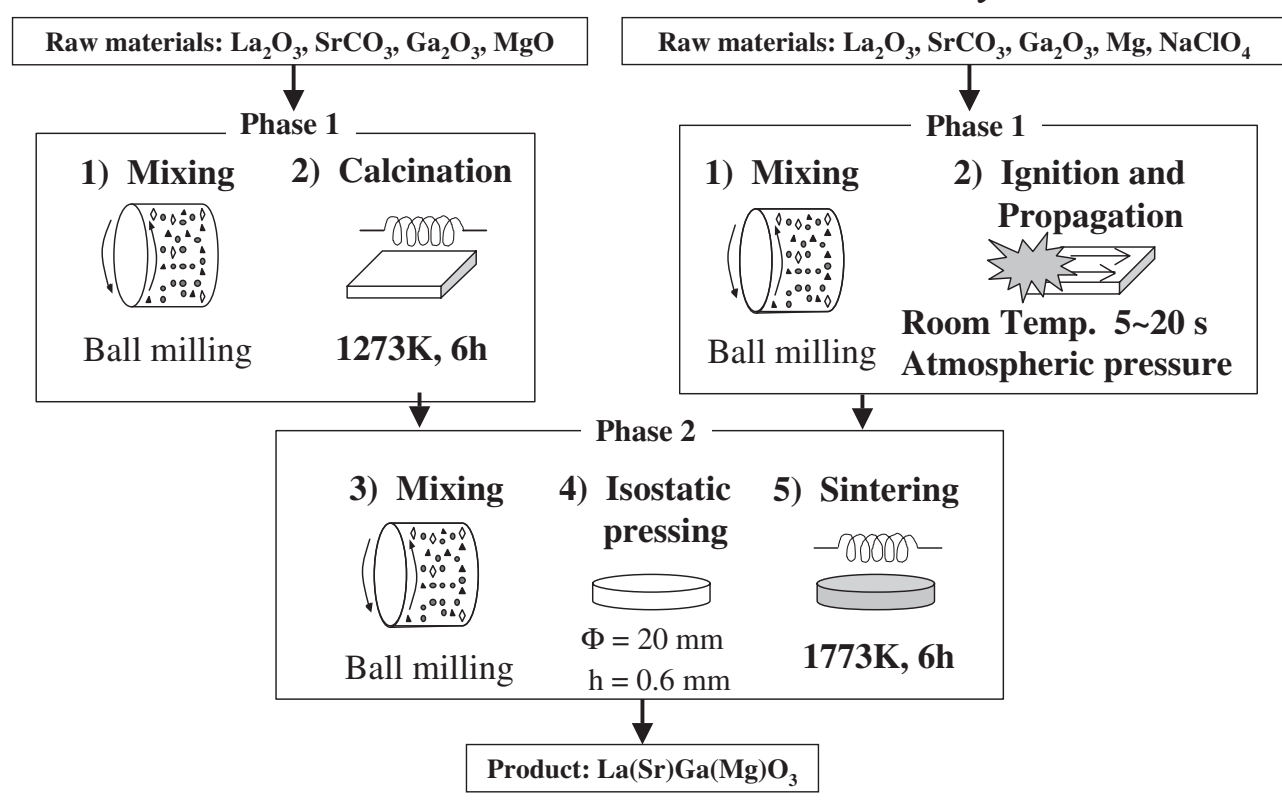

Fig. 1 Comparison of flow sheet between conventional system and proposed one for producing $\mathrm{La}(\mathrm{Sr}) \mathrm{Ga}(\mathrm{Mg}) \mathrm{O}_{3}$. $\mathrm{Note}$ that sodium perchlorate and metallic magnesium are selected for utilizing highly exothermic reaction between them in the proposed system.

Table 1 Experimental conditions for preparing samples.

\begin{tabular}{cccc}
\hline Case & $\begin{array}{c}\text { Magnesium mixing } \\
\text { molar ratio, } y /-\end{array}$ & $\begin{array}{c}\text { Atmosphere (Purity) } \\
\text { and Pressure }\end{array}$ & Temperature \\
\hline 1 & 0.8 & & \\
2 & 0.6 & Normal pressures at & \\
3 & 0.4 & Nitrogen gas (99.99\%) & Room temperature \\
4 & 0.3 & & \\
5 & 0.2 & & \\
\hline
\end{tabular}

propagates completely at the moment when one end of the mixed sample is ignited, and the product is obtained with the desired composition. (See Phase 1 in Fig. 1(b).) Oxidation of metallic magnesium was utilized in the experiment for the CS. In the conventional SSM, all the raw materials were oxides or carbonate, in contrast, sodium perchlorate was selected as an oxidizing reagent of metallic magnesium. ${ }^{7,8)}$

In the experiments, the samples were prepared from commercially available powders of lanthanum oxide (Aldrich, 99.9\% purity), strontium carbonate (Aldrich, 99.9\% purity), gallium oxide (Kojundo Chemical, 99.9\% purity), metallic magnesium (Kojundo Chemical, 99.9\% purity), and sodium perchlorate (Aldrich, 98\% purity). As seen in Table 1, the mixing molar ratio of magnesium was changed under the constant ratio of strontium carbonate; $x=0.1$ and $y=0.8,0.6,0.4,0.3$ and 0.2 in $\mathrm{La}_{1-x} \mathrm{Sr}_{x} \mathrm{Ga}_{1-y} \mathrm{Mg}_{y} \mathrm{O}_{3}$. Here, $\mathrm{La}_{0.9} \mathrm{Sr}_{0.1} \mathrm{Ga}_{1-y} \mathrm{Mg}_{y} \mathrm{O}_{3}$ compositions have been denoted by the abbreviation LSGMy.

\subsection{Experimental procedure}

Figure 2 shows a schematic diagram of the experimental apparatus used in the CS of LSGM. This system has very simple features and the initial investment is economical. It is comprised of three parts; a reactor, a gas supply system, and a vacuum system. The synthesis procedure was as follows. First, the five powders were mixed by ball milling at $60 \mathrm{rad}$ per min for $3 \mathrm{~h}$ in air; the alumina milling pot contained alumina balls of $10 \mathrm{~mm}$ in diameter. From XRD analysis of the sample mixed, the peaks of magnesium oxide were not observed after ball milling. The powder mixture was placed in a graphite crucible, $20 \mathrm{~mm} \times 30 \mathrm{~mm} \times 7 \mathrm{~mm}$, without any compressive treatment, and the weight of this sample was approximately $7 \mathrm{~g}$. Subsequently, the reactor was evacuated by a rotary pump for $10 \mathrm{~min}$ and pure nitrogen was supplied to maintain the atmospheric pressure. Finally, a disposable carbon foil that is used as an igniter, $5 \mathrm{~mm} \times 200 \mathrm{~mm} \times$ $0.1 \mathrm{~mm}$, was placed contact with one end of the sample and was electrically-flashed at $50 \mathrm{~V}$ and $100 \mathrm{~A}$ at room temperature. All the phenomena during the CS, i.e., ignition, propagation, and completion, were observed through the upper glass window of the apparatus. The products were identified by X-ray diffraction (XRD) analysis and compared with the ones obtained from the SSM. The lattice parameters were calculated on the basis of several strong peaks over a wide range of diffraction angles. In the sintering procedure, after the CS, the samples were initially pulverized with zirconia mortar in air then isostatically pressed at $275 \mathrm{MPa}$ into a $20 \mathrm{~mm}$ in diameter $\times 0.6 \mathrm{~mm}$ disk. Finally, the green compacts were sintered in a temperature range from 1273 to $1773 \mathrm{~K}$ for $6 \mathrm{~h}$ at $70 \mathrm{~V}$ and $12 \mathrm{~A}$ in air for determining the sintering temperature. (See Phase 2 in Fig. 1(a).) The polished surface of the product was also observed by scanning electron microscopy (SEM) for discussing the microstructure.

\subsection{Measurement of electrical conductivity}

The disk-shaped sample obtained after the sintering for $6 \mathrm{~h}$ 
(a) Top view

Inlet of cooling water Thermal insulator

(b) Side view

Carbon foil

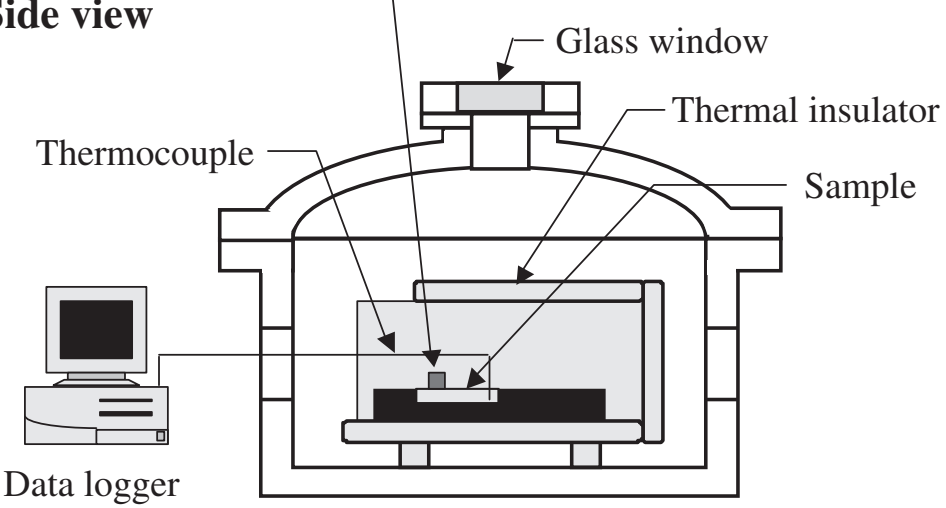

Graphite crucible

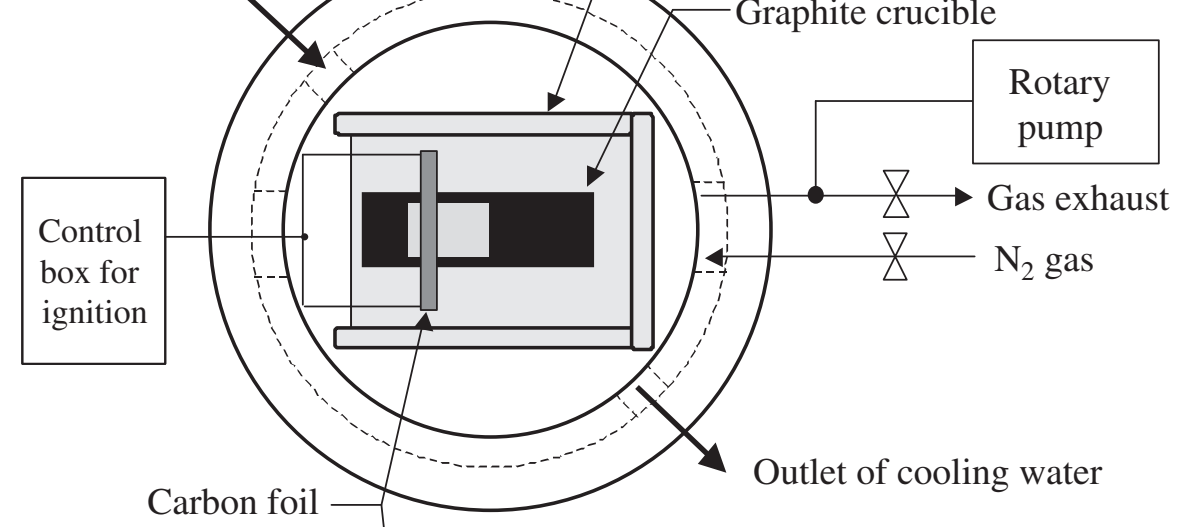

Data logger

Fig. 2 Schematic diagram of the experimental apparatus used for the combustion synthesis of $\mathrm{La}(\mathrm{Sr}) \mathrm{Ga}(\mathrm{Mg}) \mathrm{O}_{3}$.

was cut into a rectangular shape $(4 \mathrm{~mm} \times 7 \mathrm{~mm} \times 1 \mathrm{~mm})$, on both faces of which were covered by Platinum past (Tanaka Kikinzoku, TR7905). Platinum mesh connected with platinum wire was attached and then the sample was fired at $1123 \mathrm{~K}$ for $30 \mathrm{~min}$ at the flowing argon atmosphere to remove the organic solvent and to contact solidly between the mesh and the sample. After being connected the platinum wire for the potential probe, electrical conductivity was measured. Oxide ion conductivities were measured by a conventional ac two-probes technique with a frequency response analyzer (Solatron 1260) in a range from $10 \mathrm{MHz}$ to $1 \mathrm{~Hz}$. Conductivities were also measured with dc four-probe method. It was confirmed that the conductivity estimated by both methods was matched within an experimental error. The electrical conductivities of the sintered samples were measured by the dc four-probe and the two-probe methods, as a function of the oxygen partial pressure from $10^{-15}$ to $10^{5} \mathrm{~Pa}$ and temperature from 773 to $1273 \mathrm{~K}$. A cell with flowing gas was designed to measure the oxide ionic conductivity at the mixture gas of $\mathrm{N}_{2}-\mathrm{O}_{2}, \mathrm{CO}-\mathrm{CO}_{2}$ and $\mathrm{H}_{2}-\mathrm{H}_{2} \mathrm{O}$ with different mixing ratios. The oxygen partial pressure was monitored by using the oxygen sensor of calcium oxide-stabilized zirconia placed in the close proximity of the samples. The conductivity was twice measured to confirm reproducibility within $1 \%$ in experimental error.

\section{Results and Discussion}

\subsection{Combustion synthesis (CS)}

During the CS in the cases 1, 2, 3 and 4 (Table 1), the samples were successfully ignited, propagated, and the process was completed. The samples emitted a large amount of light and white smoke during the propagation. Each propagating time was very short, 5 to $20 \mathrm{~s}$; the case 1 took the shortest propagation time, and the case 4 , the longest. White smoke generation was probably due to the evaporation of sodium chloride. Overall equation in the cases 1 to 4 are explained by the following eq. (1):

$$
\begin{gathered}
0.45 \mathrm{La}_{2} \mathrm{O}_{3}+0.1 \mathrm{SrCO}_{3}+0.5(1-y) \mathrm{Ga}_{2} \mathrm{O}_{3} \\
+y \mathrm{Mg}+(0.0125+0.375 y) \mathrm{NaClO}_{4} \\
\rightarrow \mathrm{La}_{0.9} \mathrm{Sr}_{0.1} \mathrm{Ga}_{1-y} \mathrm{Mg}_{y} \mathrm{O}_{3}+0.1 \mathrm{CO}_{2}(\mathrm{~g}) \\
+(0.0125+0.375 y) \mathrm{NaCl}(\mathrm{g})
\end{gathered}
$$

However, the case 5, which was selected for producing LSGM0.2, did not cause complete propagation due to weak exothermic reaction of very small magnesium in spite of ignition.

\subsection{XRD phase analysis}

Figure 3 shows the XRD patterns of the products after the $\mathrm{CS}$ at a nitrogen atmosphere by comparing them with the reference data for LSGM0.2 after the calcination and the sintering by SSM. The peaks of LSGM0.6, LSGM0.4 and 


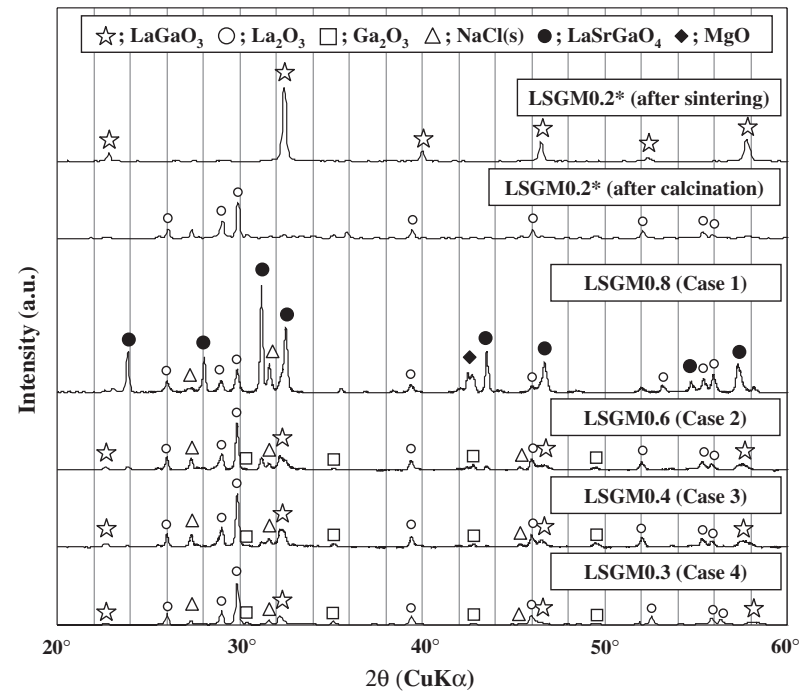

Fig. 3 XRD patterns of the combustion-synthesized products. Asterisk (*) is reference sample obtained by the conventional solid-state method.

Table 2 Estimated ratios of the lattice parameter of the produced LSGMy.

\begin{tabular}{ccc}
\hline \multirow{2}{*}{ Products } & \multicolumn{2}{c}{ Lattice parameter ratio/_ } \\
\cline { 2 - 3 } & $\mathrm{a} / \mathrm{b}$ & $\mathrm{c} / \mathrm{b}$ \\
\hline LSGM0.6 & 1.03 & 1.44 \\
LSGM0.4 & 1.03 & 1.46 \\
LSGM0.3 & 0.998 & 1.41 \\
LSGM0.2 $^{*}$ & 0.996 & 1.41 \\
LaGaO $_{3}^{*}$ & 0.994 & 1.40 \\
\hline
\end{tabular}

${ }^{*}$ Reference data, obtained from JCPDS card.

LSGM0.3 were in good agreement with those of LSGM0.2 after the calcination. However, the peak of an unreacted lanthanum oxide indicated that purity of LSGM phase was not enough. Solid sodium chloride was also detected as impurity, implying that the sublimation of gas into solid might be occurred. In contrast, lanthanum strontium gallium oxide $\left(\mathrm{LaSrGaO}_{4}\right)$ and magnesium oxide were observed in the experiment of LSGM0.8, which was not similar to a perovskite type oxide. From the phase identification of the products with impurity, we judged that the CS was just like the calcination process in the conventional SSM, not the sintering one.

Table 2 gives the estimated lattice parameter ratios of LSGM0.6, LSGM0.4, and LSGM0.3 that are produced in each case. The reference data for LSGM0.2 and lanthanum gallate $\left(\mathrm{LaGaO}_{3}\right)$ of SSM are also listed. The crystal structure of lanthanum gallate-based perovskite oxide is known to be orthorhombic (Pbnm) at room temperature. ${ }^{9)}$ The lattice parameter of the produced LSGMy gradually increased with increasing the mixing molar ratio of magnesium up to LSGM0.4. In increasing magnesium at the gallium site, we can easily predict the existence of the limitation of magnesium substitution ratio, because the ionic radius of magnesium, $0.072 \mathrm{~nm}$, is larger than that of gallium, $0.062 \mathrm{~nm}$. As the collateral evidence of the prediction, the lattice parameters of LSGM0.6 were almost the same as those of LSGM0.4 and the product of LSGM0.8 was completely

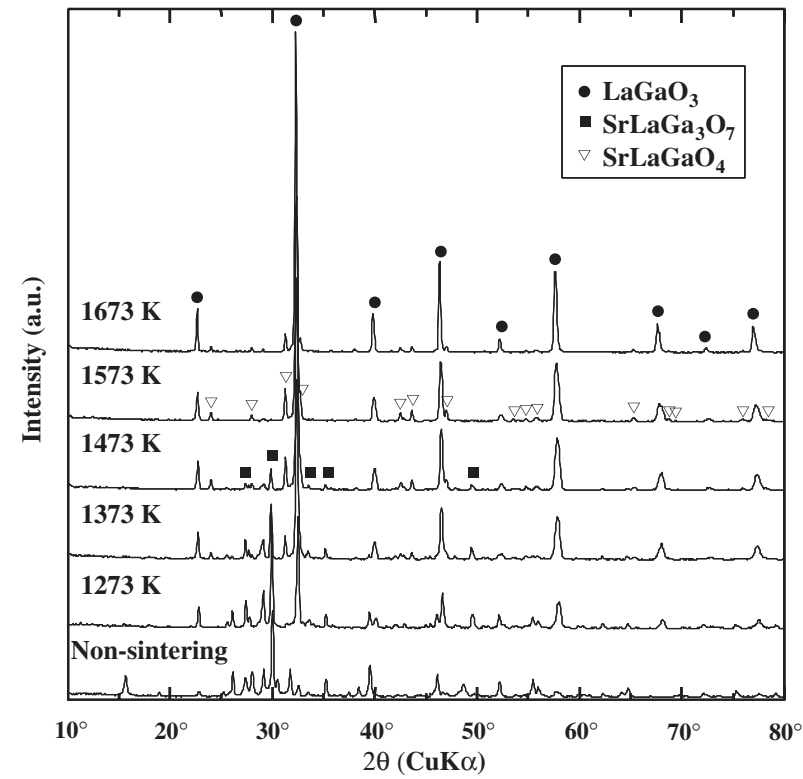

Fig. 4 XRD patterns of the LSGM0.3 samples sintered at constant temperatures from 1273 to $1673 \mathrm{~K}$ after combustion synthesis.

different from the perovskite structure of lanthanum gallate, due to magnesium saturation. In conclusion, the CS successfully produced doped-lanthanum gallate perovskite type oxides, LSGM0.6, LSGM0.4 and LSGM0.3.

\subsection{Sintering behavior of LSGM0.3 sample}

Figure 4 shows XRD patterns of the LSGM samples sintered in the range of 1273 to $1673 \mathrm{~K}$ after the CS. The second phases, $\mathrm{SrLaGa}_{3} \mathrm{O}_{7}$ and $\mathrm{SrLaGaO}_{4}$, as well as the main phase of lanthanum gallate were still observed at samples sintered at 1273 to $1573 \mathrm{~K}$. However, the peaks of the sample sintered at $1673 \mathrm{~K}$ for $6 \mathrm{~h}$ agreed completely with those at $1773 \mathrm{~K}$ by the SSM. The combustion-synthesized sample with post-sintering at $1673 \mathrm{~K}$ showed blistered color, in contrast the sample was still cream color when being sintered at the same $1673 \mathrm{~K}$ in the SSM. According to Archimedes method using ethanol, the relative density of the sample was approximately $98 \%$ which was the same as the one prepared by SSM. Figure 5 shows the microstructure of the LSGM0.3 sample, in comparison to the SSM. The average grain size of the LSGM0.3 sample was approximately 5 to $10 \mu \mathrm{m}$, which was the same size as previously reported. ${ }^{10)}$ The surface of the sample sintered at $1673 \mathrm{~K}$ after the CS was smooth without any voids, although that of the sample prepared by the SSM was observed some voids. It revealed that the combustion-synthesized sample was completely sintered at only $1673 \mathrm{~K}$ for $6 \mathrm{~h}$, however the same thermal conditions at $1673 \mathrm{~K}$ was not enough for sintering the sample in the SSM. This is probably due to the fact that the CS generated fine powders with the perovskite phase of lanthanum gallate. As a result, the CS can lower the sintering temperature at least $100 \mathrm{~K}$ than that in the SSM.

\subsection{Electrical conductivity of LSGM samples}

Figure 6 shows the electrical conductivity of LSGMy products at $1223 \mathrm{~K}$ as a function of oxygen partial pressure in 

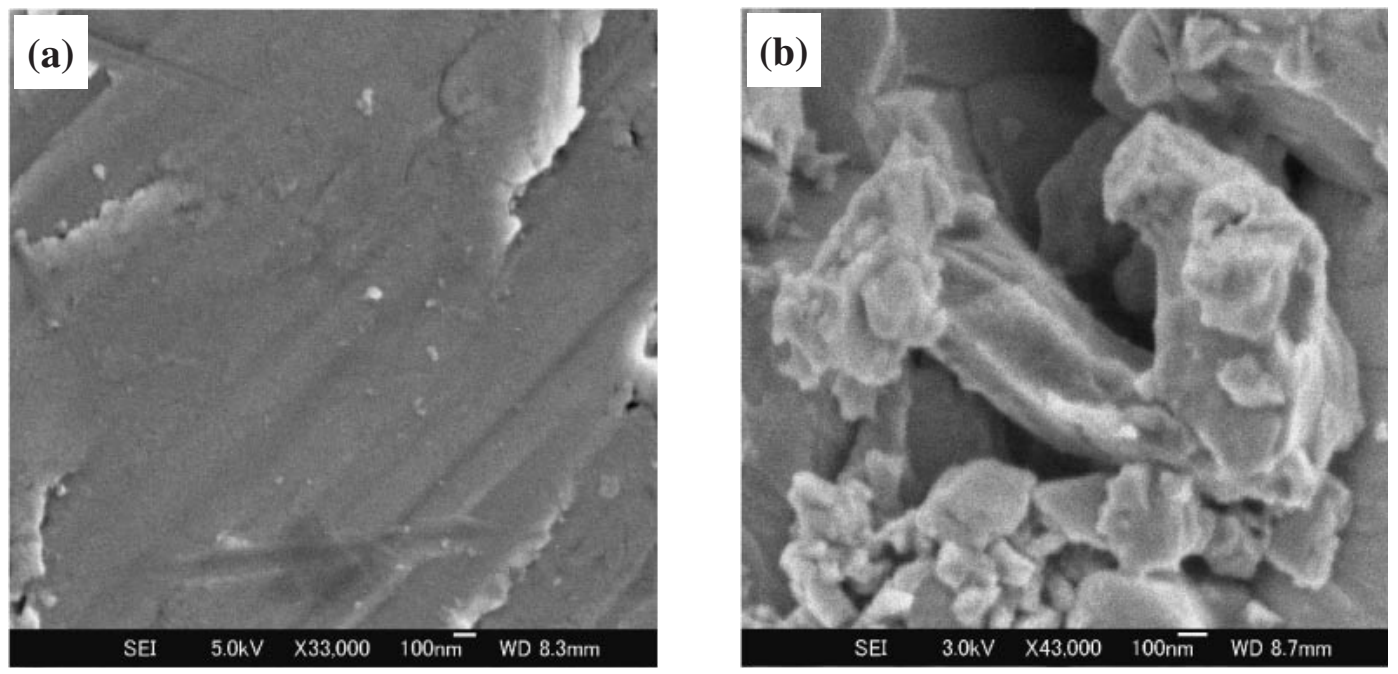

Fig. 5 SEM images of LSGM0.3 electrolytes prepared by different methods: (a) sintering at $1673 \mathrm{~K}$ after combustion synthesis and (b) solid-state method at $1673 \mathrm{~K}$.

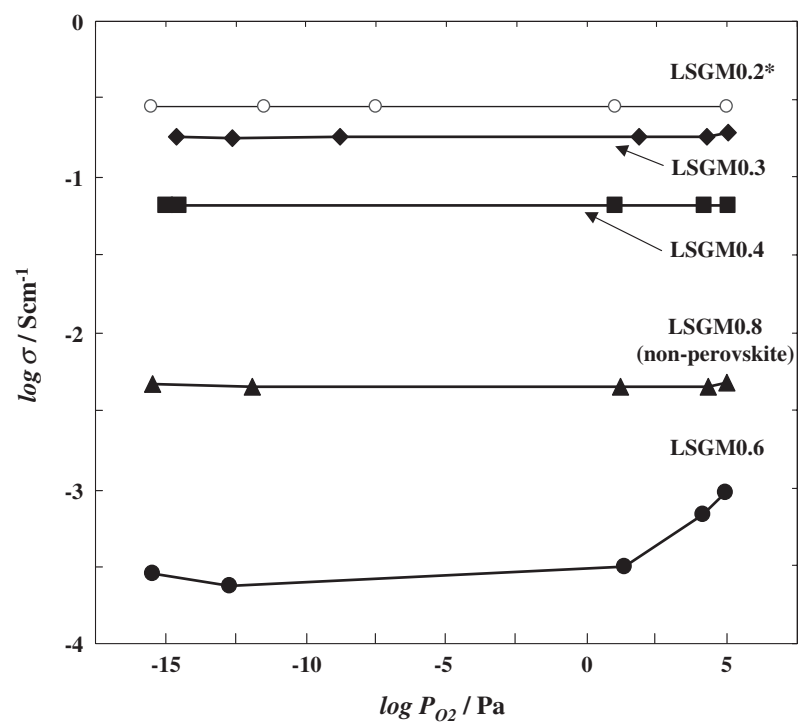

Fig. 6 Electrical conductivities of the LSGMy produced at $1223 \mathrm{~K}$ as a function of oxygen partial pressure. Asterisk $(*)$ is reference sample obtained by the solid-state method.

the range from $10^{-15}$ to $10^{5} \mathrm{~Pa}$. In this range, the electrical conductivities of LSGM0.3, LSGM0.4 and LSGM0.8 (nonperovskite) were independent of the oxygen partial pressure; especially, the electrical conductivity of LSGM0.3 was the highest, $0.18 \mathrm{Scm}^{-1}$ at $1223 \mathrm{~K}$, which was the comparable value to that of LSGM0.2 by SSM $\left(0.28 \mathrm{Scm}^{-1}\right.$ at $\left.1223 \mathrm{~K}\right)$. Moreover, the electrical conductivities of perovskite oxide, LSGM0.3, 0.4 and 0.6, increased with decreasing magnesium mixing molar ratio. In contrast, the electrical conductivity of LSGM0.6 abruptly increased at high oxygen partial pressure $\mathrm{P}_{\mathrm{O}_{2}}=1$ to $10^{5} \mathrm{~Pa}$ ). This was likely caused by the fact that the hole conduction was dominant here. As for the appearance of the hole conduction, the following eq. (2) using the KrögerVink notation can be anticipated.

$$
1 / 2 \mathrm{O}_{2}+\mathrm{V}_{\mathrm{O}}^{\bullet \bullet}=\mathrm{O}_{\mathrm{O}}{ }^{x}+2 \mathrm{~h}^{\bullet}
$$

Here, $\mathrm{V}_{\mathrm{O}}^{\bullet \bullet}$ is an oxygen ion vacancy, $\mathrm{O}_{\mathrm{O}}{ }^{x}$ is an oxide ion and

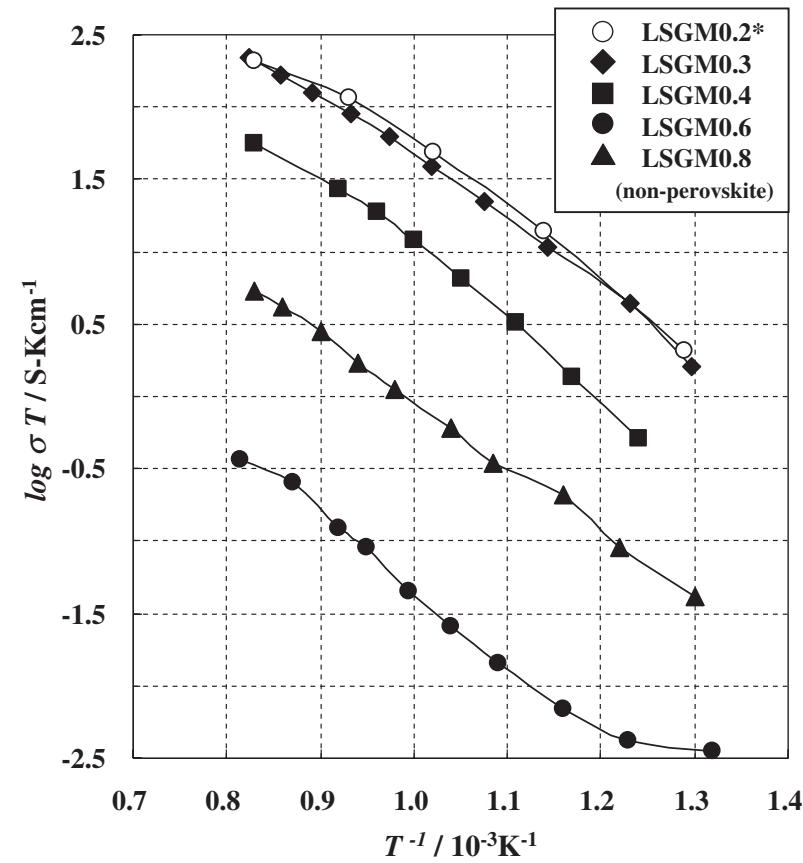

Fig. 7 Arrhenius plots of electrical conductivity of the LSGMy produced at $\mathrm{P}_{\mathrm{O}_{2}}=1 \mathrm{~Pa}$. Asterisk $(*)$ is reference sample obtained by the solid-state method.

$\mathrm{h}^{\bullet}$ is an electron hole. According to this equation, excess oxygen was introduced into the lattice and the hole conduction increased with $\mathrm{P}_{\mathrm{O}_{2}}{ }^{1 / 4}$. In any case, it is worth noting that the perovskite type oxides of LSGM0.3 and LSGM0.4 produced by the CS are an oxide ionic conductor across a wide range of oxygen partial pressure.

Figure 7 shows the Arrhenius plots of the electrical conductivity of the LSGMy produced, in which all of the data were measured in the air atmosphere. From this figure, it was clear that the electrical conductivities of all products showed positive dependences up to $1273 \mathrm{~K}$ in temperature. In particular, the plots of LSGM0.3 were in fairly good agreement with those of LSGM0.2 produced by the SSM. 
Table 3 Comparison between the conventional solid-state method and the proposed one based on the combustion synthesis from the viewpoint of primary energy consumption and carbon dioxide emission.

(a) Primary energy consumption (MJ/kg-LSGM0.3 product)

\begin{tabular}{|c|c|c|}
\hline \multirow[b]{2}{*}{ Phase } & \multicolumn{2}{|c|}{ Production Method } \\
\hline & Solid-state method & $\begin{array}{l}\text { Combustion synthesis } \\
\text { with sintering }\end{array}$ \\
\hline $\begin{array}{l}\text { Production Process } \\
\text { of Raw Material }\end{array}$ & 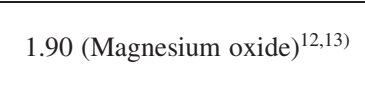 & $\begin{array}{l}7.16 \text { (Metallic magnesium) }^{14-16)} \\
3.73 \text { (Sodium perchlorate) }^{17)}\end{array}$ \\
\hline LSGM0.3 Production & $\begin{array}{c}18.1 \text { (Calcination) } \\
18.1 \text { (Sintering) }\end{array}$ & $\begin{array}{c}0.833 \text { (Combustion synthesis) } \\
18.1 \text { (Sintering) }\end{array}$ \\
\hline Total & 38.1 & $29.8(\mathbf{\Delta} 8.3)$ \\
\hline \multicolumn{3}{|c|}{ (b) Carbon dioxide emission ( $\mathrm{kg}-\mathrm{CO}_{2} / \mathrm{kg}-\mathrm{LSGM} 0.3$ product) } \\
\hline \multirow[b]{2}{*}{ Phase } & \multicolumn{2}{|c|}{ Production Method } \\
\hline & Solid-state method & $\begin{array}{l}\text { Combustion synthesis } \\
\text { with sintering }\end{array}$ \\
\hline $\begin{array}{c}\text { Production Process } \\
\text { of Raw Material }\end{array}$ & 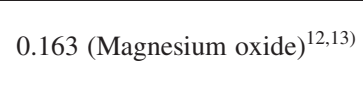 & $\begin{array}{c}0.564 \text { (Metallic magnesium) }^{14-16)} \\
0.188 \text { (Sodium perchlorate) }^{17)}\end{array}$ \\
\hline LSGM0.3 Production & $\begin{array}{c}1.91^{*} \text { (Calcination) } \\
1.91^{*} \text { (Sintering) }\end{array}$ & $\begin{array}{c}0.0873^{*} \text { (Combustion synthesis) } \\
1.91^{*} \text { (Sintering) }\end{array}$ \\
\hline Total & 3.98 & $2.75(\mathbf{\Delta} 1.23)$ \\
\hline
\end{tabular}

${ }^{*}$ Calculated from the product both electric energy $(\mathrm{kWh})$ and $\mathrm{CO}_{2}$-exhaust coefficient $\left(0.378 \mathrm{~kg}-\mathrm{CO}_{2} / \mathrm{kWh}\right){ }^{18)}$

The Arrhenius plots exhibited two different slopes, one in the high range, i.e., from 873 to $1273 \mathrm{~K}$, and the other in the low range, i.e., below $873 \mathrm{~K}$; the activation energy calculated for the electrical conductivity was $0.72 \mathrm{eV}$ for the high range and $0.98 \mathrm{eV}$ for the low range. The result showed that LSGM0.3 was a pure oxide ionic conductor in the range from 873 to $1273 \mathrm{~K}$, and the change in activation energy at $873 \mathrm{~K}$ was caused by the phase transition from monoclinic (pseudorhombohedral) to rhombohedral. ${ }^{11)}$ In the case of LSGM0.6, an irregularity was also detected at approximately 1273 and $833 \mathrm{~K}$ because the holes became dominant as shown in Fig. 6. Among four samples, LSGM0.3 was the most applicable to an electrolyte of SOFC above $873 \mathrm{~K}$.

\subsection{Energy consumption and carbon dioxide emission in the LSGM production}

Table 3 gives the comparison between the two production methods from the two points: (a) primary energy consumption (PEC) and (b) carbon dioxide emission (CDE) per a kilogram of LSGM0.3 product. In doing the assessment, we focused on the differences between the production processes of raw materials and the LSGM0.3-electrolyte. The production processes of magnesium oxide, metallic magnesium and sodium perchrolate were rigorously estimated from several reliable literatures, ${ }^{12-17)}$ while common processes, the milling and production of lanthanum oxide and strontium carbonate and gallium oxide, were not considered here. In order to evaluate PEC of the LSGM0.3 production, the actual experimental data, i.e., voltage and current required for the electric furnace or ignition and a processing time, were employed. Furthermore, CDE in the LSGM0.3 production was calculated by using PEC of the LSGM0.3 production and the carbon dioxide exhaust coefficient $\left(0.378 \mathrm{~kg}-\mathrm{CO}_{2} /\right.$ $\mathrm{kWh}) .{ }^{18)}$ As a result, the $\mathrm{CS}$, requesting the preparations of metallic magnesium and sodium perchrolate, had much smaller values in both PEC and CDE than the calcination process. Therefore, the CS had more advantages: it decreased 8.3 MJ for PEC and $1.23 \mathrm{~kg}-\mathrm{CO}_{2} / \mathrm{kg}$-LSGM0.3 product for $\mathrm{CDE}$ in comparison to the conventional SSM.

\section{Conclusions}

The CS of LSGM was experimentally and theoretically studied by comparing with the conventional SSM. The following conclusions were derived.

(1) The CS of LSGM with different molar ratios of magnesium, LSGM0.3, LSGM0.4 and LSGM0.6, at nitrogen atmosphere were very successfully carried out, which can replace the time- and energy-consuming calcination process in the conventional SSM.

(2) The CS released thermal conditions in the sintering process as final phase. The sintering temperature of LSGM0.3 after the CS was only $1673 \mathrm{~K}$, which was at least $100 \mathrm{~K}$ lower than that in the conventional SSM.

(3) Electrical conductivity of the LSGM obtained increased with decreasing the mixing molar ratio of magnesium and with increasing temperature, in contrast it was significantly constant and stable due to high ionic conductivity across a wide range of oxygen partial pressures. Among the four samples obtained, LSGM0.3 showed the highest values, which was almost the same as the world record.

(4) According to the life cycle assessment, energy consumption and carbon dioxide emission in the $\mathrm{CS}$ of LSGM0.3 decreased $8.3 \mathrm{MJ}$ and $1.23 \mathrm{~kg}-\mathrm{CO}_{2} / \mathrm{kg}$ LSGM0.3 product, in comparison to the conventional SSM.

We conclude that from the viewpoints of electrical conductivity and life cycle assessment of energy consumption and carbon dioxide emission, the CS is very practical for producing an improved LSGM electrolyte in the intermediate-temperature SOFC system. 


\section{Acknowledgement}

This research was partially supported by the national project "Demonstration of Green-Hydrogen Community in Honjo-Waseda area", Ministry of the Environment, Japan.

\section{REFERENCES}

1) T. Ishihara, H. Matsuda and Y. Takita: J. Am. Chem. Soc. 116 (1994) 3801-3803.

2) T. Ishihara, M. Honda, T. Shibayama, H. Minami, H. Nishiguchi and Y. Takita: J. Electrochem. Soc. 145 (1998) 3177-3182.

3) T. Ishihara, H. Minami, H. Matsuda, H. Nishiguchi and Y. Takita: Chem. Commun. 8 (1996) 929-930.

4) Z. A. Munir and U. Anselmi-Tamburini: Self-Propagating Exothermic Reactions: The Synthesis of High Temperature Materials by Combustion, (North-Holland, 1989), pp. 277-365.

5) T. Akiyama, Y. Hirai and N. Ishikawa: Mater. Trans. 42 (2001) 460463.

6) T. Akiyama, H. Isogai and J. Yagi: Int. J. Self-Propag. High-Temp. Syn. 4 (1995) 69-77.

7) A. A. Shiryaev, M. D. Nersesyan, Q. Ming and Dan Luss: J. Mater. Syn.
Proc. 7 (1999) 83-90.

8) Q. Ming, M. D. Nersesyan, J. T. Richardson and Dan Luss: J. Mater. Sci. 35 (2000) 3599-3606.

9) Y. Wang, X. Liu, G. D. Yao, R. C. Liebermann and M. Dudley: Mater. Sci. Eng. A 132 (1991) 13-21.

10) K. Huang, R. Tichy and J. B. Goodenough: J. Am. Ceram. Soc. 81 (1998) 2576.

11) P. R. Slater, J. T. S. Irvine, T. Ishihara and Y. Takita: J. Solid State Chem. 139 (1998) 135-143.

12) R. H. Perry, D. W. Green and J. O. Maloney: Perry's Chemical Engineers' Handbook 6th edition, (McGraw-Hill, 1984) pp. 20-36.

13) W. Buchner: Industrial Inorganic Chemistry (Weinheim, 1933).

14) P. F. Chapman and F. Roberts: Metal Resources and Energy (Butterworths, 1983).

15) Minerals Yearbook, Section Minerals (the Bureau of Mines, the United States, 1989).

16) Inventory Data of Materials (IDEMAT) (Delft University Clean Technology Institute, 1995).

17) Forests and Landscape (FOEFL or BUWAL) Environmental Series No. 132 (Swiss Federal Office of Environment, Switzerland, 1991) pp. A59.

18) Guideline for Calculation Method of Green House Gas Emission from Trade Association (Ministry of the Environment, Japan, 2003) pp. 2-7. 